\title{
Identifikasi Cendawan Penyebab Penyakit Moler Pada Tanaman Bawang Merah (Allium Ascolonicum L.) Di Kabupaten Enrekang
}

\author{
Hikmahwati $^{1 *}$, Muhammad Rifqy Auliah ${ }^{2}$, Ramlah $^{3}$ dan Fitrianti ${ }^{4}$ \\ ${ }^{1234}$ Jurusan Agroteknologi, FakultasIlmu Pertanian, Universitas AlAsyariah Mandar, \\ Jl. BudiUtomo No 2, Manding, PolewaliMandar, Sulawesi Barat 91311, Indonesia
}

*Email : hikmahwatihasen@gmail.com

\begin{abstract}
Abstrak
Bawang merah (Allium ascolonicum L.) ialah kelompok hortikultura yang mempunyai banyak khasiat, serta ialah salah satu dari 10 komoditas hortikultura yang difokuskan pengembangannya di Indonesia. Produksi Bawang Merah di Kabupaten Enrekang pada tahun 2018 sebanyak 73. 58 ton, tetapi terjadi penerunan dari tahun 2017 sebesar 111. 61 ton. Salah satu gangguan di dalam upaya kenaikan produksi bawang merah ialah terdapatnya penyakit tumbuhan yang diakibatkan oleh cendawan. Tujuan riset untuk mengenali tipe serta morfologi cendawan patogen pada tumbuhan bawang merah di Kabupaten Enrekang. Studi dilakukan di Kecamatan Anggeraja, Kabupaten Enrekang dan di Laboratorium Penyakit Tumbuhan, Universitas Hasanuddin. Prosedur Peneliatan adalah : (a) Pengambilan tanaman bergejala memakai tata cara Purpossive Randomized Sampling( b) Persiapan Media tumbuh, yaitu Media PDA( Potato Dextro Agar),( c) Isolasi serta Identifikasi Cendawan. Hasil peneilitian memperlihatkan corak koloni pada pengamatan makroskopis yaitu bercorak putih, kream dan keunguan, serta pengamatan mikroskopis menampilkan makrokonidia semacam bulan sabit yang memanjang, ataupun berupa pipih memanjang dengan kedua ujungnya runcing serta mempunyai 2- 3 sekat, mikrokonidia lonjong, panjang, bagian tengah ramping serta kedua ujung tumpul, serta terdapat pula yang berupa oval. Isolat yang diperoleh disimpulkan sebagai tipe Fusarium oxysporum pemicu penyakit moler pada tumbuhan bawang merah di Kabupaten Enrekang.
\end{abstract}

Kata Kunci : bentuk morfologi, makroskopis, mikroskopis, makrokonidoa, mikrokonidia

\section{Pendahuluan}

Bawang merah (Allium ascolonicum L.) merupakan satu dari sepuluh kelompok hortikultura yang dikembangkan di Indonesia. Salah satu sentra produksi tanaman bawang merah di Indonesia berada di Sulawesi selatan yaitu Kabupaten Enrekang, dengan produksi pada tahun 2018 sebanyak 73.58 ton (Statistik, 2019), namun mengalami penerunan dari produksi tahun 2017 sebesar 111.61 ton (Bada Pusat Statistik, 2018)

Usaha peningkatan produksi bawang merah sering terkendala adanya patogen penyebab penyakit yang berasal dari kelompok cendawan antara lain Fusarium Oxysporum f.sp. cepae penyebab penyakit busuk pangkal batang atau disebut juga penyakit moler (Prakoso et al., 2016). Penyakit moler mampu menurunkan produksi bawang merah.

Beberapa pengendalain yang digunakan untuk mencegah terjadinya serangan penyakit yang disebabkan oleh cendawan Fusarium oxysproum diantaranya penggunaan agensia hayati, penggunaan bakteri antagonis (Quyen et al., 2017) telah dilakukan untuk menekan Fusarium spp. dengan perlakuan penyiraman atau penyelubungan pada benih, bakteri Pseudomonas flourescens juga dapat menekan penyakit moler dan mampu meningkatkan pertumbuhan tanaman (Santoso et al, 2007), pemanfaatan Trichoderma sp. dilaporkan dapat mengendalian penyakit moler dan adanya positif pada pertumbuhan tanaman (Deden dan Umiyati, 2017). Pengembangan jamur di sekitar perakaran tanaman bawang merah sebagai agen antagonis juga sudah dilakukan oleh (Nugroho, 2015). Penggunaan kultivar tahan juga dilaporkan telah mengurangi intesitas serangan moler sebanyak 60\% (Prakoso et al., 2016 dan Aprilia et al, 2020) selain itu varietas tahan juga meningkatkan hasil pertumbuhan tanaman (Karim et al., 2020)

Pengendalian penyakit pada tanaman bawang merah di Kecamatan Anggeraja, Kabupaten Enrekang masih bertumpu pada penggunaan pestisida. Sejumlah 63 jenis pestisida, sembilan diantaranya tidak terdaftar resmi, petani di Kecamatan Anggeraja sebanyak 65\% menyemprot pestisida secara intesif dua hari sekali. Petani yang menambah dosis hingga $900 \%$ sebanyak $22 \%$ dan melakukan pencampuaran berbagai jenis dan merek pestisida karena menginginkan efektivitas (Zulfikar, 2017). Perilaku ini memicu resistensi cendawan patogen terhadap fungisida sehingga semakin sulit menekan penyakit pada pertanaman bawang merah di Kabupaten Enrekang.

Berdasarkan permasalahan tersebut di atas maka perlu dilakukan penelitian untuk megidentifikasi secara morfologi cendawan patogen penyebab penyakit moler pada tanaman bawang merah di kabupaten Enrekang sehingga bisa dirumuskan pengendalian hayati yang tepat sasaran dan spesifik lokasi.

\section{Kerangka Teori}

\subsection{Bawang Merah (Allium ascalonicum L.)}

Bawang merah (Allium ascalonicum L.) adalah tanaman semusim yang berbentuk rumpun dan tumbuh tegak, memiliki tinggi tanaman 15-40 cm. Menurut 
(Tjitrosoepomo, 2010) kalsifikasi bawang merah adalah sebagai berikut:

$\begin{array}{ll}\text { Kingdom } & \text { : Plantae } \\ \text { Divisi } & \text { : Spermatophyta } \\ \text { Subdivisi } & : \text { Angiospermae } \\ \text { Kelas } & \text { : Monocotyledonae } \\ \text { Ordo } & \text { : Liliales } \\ \text { Famili } & \text { : Liliaceae } \\ \text { Genus } & : \text { Allium } \\ \text { Spesies } & : \text { Allium ascalonicum L. }\end{array}$

\subsection{Morfologi Bawang Merah}

Morfologi bawang merah terdiri dari beberapa bagian yaitu akar, batang, daun, bunga, buah dan biji. Daun berbentuk silindris berlubang, berwarna hijau muda dengan ukuran 50-70 cm, letak daun terdapat pada tangkai yang relatif pendek. Bunga berbentuk payung dan berwarna putih dan keluar dari ujung tanaman (titik tumbuh). Bawang merah memiliki umbi dengan bentuk oval dan berwarna ungu/putih dengan akar serabut yang dangkal, bercabang dan tersebar, batang berupa batang sejati atau discus seperti cakram, tipis, pendek dan ditempati melekatnya akar dan mata tunas, batang semu terletak diatas discus dan tersusun dari beberapa pelepah daun dan batang semu di dalam tanah yang kemudian berubah bentuk dan fungsi sebagai umbi lapis. (Sianipar, et al., 2018)

\subsection{Penyakit moler atau layu Fusarium (Twisting Disease) Pada Tanaman Bawang Merah}

Fusarium oxysporum f.sp. cepae Schlechtend.:Fr. (Hans $\mathrm{HN}$ ), Snyder WC, Hans HN. (FOCe) merupakan patogen yang menyebabkan busuk pangkal pada bawang merah (Fourie et al., 2009). Patogen ini menyerang akar dan umbi, gejala yang muncul berupa pembusukan akar, perubahan warna hingga nekrosis di dasar umbi lapis terlihat koloni jamur berwarna putih dan Apabila umbi lapis dipotong membujur maka terlihat adanya pembusukan berawal dari dasar umbi meluas ke atas maupun ke samping (Ratih et al, 2017). Gejala visual pada daun menunjukkan daun tida tumbuh tegak tetapi meliuk karena batang semu tumbuh lebih panjang, warna daun hijau pucat atau kekuningan dan sedikit layu (Prakoso et al., 2016). Tanaman sangat mudah tercabut karena pertumbuhan akar terganggu bahkan membusuk. Adanya gejala kematian tanaman dan menurunkan secara nyata tinggi tanaman (Isniah dan Widodo, 2015)

Mekanisme serangan Fusarium oxysporum f. sp cepae adalah dengan mengkoloni atau memperbanyak diri di area perakaran kemudian memparasit dan menghambat proses pengangkutan air serta hasil fotosintat ke seluruh bagian tanaman, pada fase berikutnya Fusarium oxysporum f.sp cepae mengeluarkan toksin yang berjenis mikotoksin dan famoniris yang dapat mengubah kelenturan selaput plasma pada daun bawang merah hal itulah yang menyebabkan daun meliuk (Prakoso et al,, 2016)

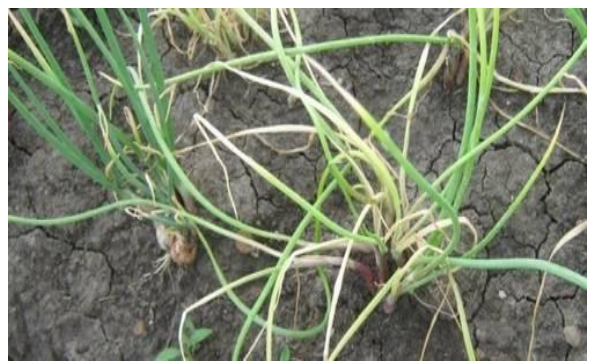

Gambar 1 : Gejala visual pada daun daun tidak tumbuh tegak tetapi meliuk karena batang semu tumbuh lebih panjang, warna daun hijau pucat atau kekuningan dan sedikit layu (Prakoso et al., 2016)

Fusarium spp. memiliki koloni yang berwarna putih, kream atau disertai warna ungu, ungu muda atau merah muda pada pusat koloninya.(Sari et al., 2017)(Sutejo et al., 2008) Pada isolat yang membentuk sporodokium dalam jumlah yang banyak, koloni akan berubah dari putih menjadi oranye. Hasil pengamatan secara makroskopis ini juga menunjukkan bahwa beberapa isolat mampu membentuk koloni dengan warna yang berbeda jika ditumbuhkan pada medium yang sama. Hal ini menunjukkan bahwa jamur ini tidak stabil dan mudah sekali mengalami mutasi (Sutejo et al., 2008).

Identifikasi Fusarium spp dapat dilakukan dengan karakterisasi morfologi untuk penentuan jenis, bentuk makrokonidia, mikrokonidia dan klamidospora dapat dijadikan penanda, meskipun metode ini sangat dipengaruhi oleh mutasi. (Leslie, 2006), Fusarium spp umumnya memiliki makrokonidia yang Melengkung, ujung runcing, memiliki 2-3 sekat, dan mikirokonidia berbentuk oval, bulat dan ada yang melengung dengan sekat 0-1 (Sari et al., 2017).

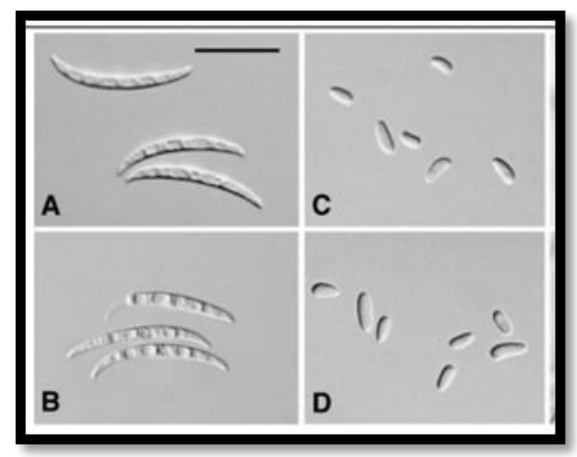

Gambar 2 : A-B Makrokonidia, C-D Mikrokonidia (Leslie dan Sumerrell, 2006)

Karakterisasi fisiology dapat digunakan untuk identifikasi, berupa tingkat pertumbuhan, produksi mikotoxin dan metabolit sekunder,dan dengan diagnosa molekuler (Leslie, 2006).

Ukuran makrokonidioa dan mikrokonidia dipengaruhi oleh keadaan lingkungan, utamanya suhu dan kelembaban. (Susanti et al, 2016)Isolat jamur Fusarium oxysporum f.sp. cepae tumbuh dengan baik pada kisaran suhu $30^{\circ} \mathrm{C}-33^{\circ} \mathrm{C}$ dan kelembaban rata-rata $85 \%$, namun perbedaan iklim ini tidak memberikan efek perubahan bentuk konidia. 


\section{Metodologi}

\subsection{Tempat dan Waktu}

Penelitian dilaksanakan di beberapa desa sentra pertanaman bawang merah di Kabupaten Enrekang, Provinsi Sulawesi Selatan dan di Laboratorium Penyakit Tumbuhan, Universitas Hasanuddin, Makassar, yang dilaksanakan pada bulan Maret - Desember 2020.

\subsection{Metode Pelaksanaan}

\subsubsection{Pengambilan Sampel Cendawan}

Sampel tanaman sakit diambil dengan menggunakan metode purpossive randomized sampling, berdasarkan daerah sentra produksi bawang dan endemik dibeberapa Desa di Kecamatan Anggeraja dan Baroko, Kabupaten Enrekang, Sulawesi Selatan. Sampel yang diambil adalah seluruh bagian tanaman sakit, dimasukkan ke dalam kantong kertas dan dibawa ke Laboratorium Penyakit tumbuhan, Universitas Hasanuddin untuk diisolasi.

\subsubsection{Persiapan Medium Tumbu}

Media yang digunakan adalah Potato Dextrose Agar (PDA). Medium tumbuh dibuat dengan campuran bahanbahan yaitu kentang yang telah dikupas $200 \mathrm{~g}$, gula pasir 20 $\mathrm{g}$, tepung agar $16 \mathrm{~g}$, aquades $1.000 \mathrm{ml}$. Pembuatan medium dengan cara mengiris kentang setebal $1 \mathrm{~cm}$, direbus sampai diperoleh air rebusan yang kekuning-kuningan yaitu ketika kentang mulai lunak. Air rebusan kentang disaring dengan menggunakan kain saring. Filtrat hasil saringan air rebusan kentang tersebut ditambahkan dengan gula pasir dan tepung agar kemudian semua bahan dipanaskan dan di aduk sampai larut. Setelah semua bahan-bahan larut, medium tumbuh tersebut disterilkan di autoclave selama \pm 15 menit pada suhu $121^{\circ} \mathrm{C}$ dengan tekanan $1,5 \mathrm{~atm}$. Saat medium tumbuh dalam keadaan hangat diberi streptomycin sulfate yang berfungsi sebagai antibiotik penghambat bakteri kontaminan. Kemudian larutan medium tumbuh dituang dalam cawan steril, selanjutnya dibiarkan pada laminator air flow sampai memadat.

\subsubsection{Isolasi Cendawan dari tanaman bawang merah}

Sampel tanaman sakit dibawa ke Laboratorium kemudian dicuci dengan air mengalir hingga bersih kemudian di potong kecil-kecil (4mm). Sterilisasi permukaan dilakukan dengan menggunakan $\mathrm{NaOCl} 2.5 \%$ selama 3 minutes dan etanol $70 \%$ selama 2 menit kemudian dicuci dengan air steril selama 1 menit. Jaringan tanaman sakit diletakkan di kertas saring steril sampai kering kemudian dipindahkan pada media biakan (PDA).Inkubasi cendawan dilkakukan pada suhu ruangan selama 3-14 hari. Pemindahan koloni baru dilakukan berulangulang sampai diperoleh isolat murni.

\subsubsection{Identifikasi Cendawan}

Identifikasi dilakukan dengan mengamati ciri makroskopis dan mikroskopis cendawan. Ciri makroskopis yang diamati adalah warna dan koloni cendawan. Pengamatan ciri mikroskopis mencakup spora atau konidia cendawan.
Mendokumentasikan isolat dengan menggunakan mikroskop berkamera. Identifikasi dilakukan dengan mengacu pada buku Laboratorium untuk Fusarium .

\section{Hasil dan Pembahasan}

Berdasarkan hasil isolasi dari sampel yang diperoleh dari beberapa desa di kabupaten Enrekang diperoleh beberapa isolat yang relatif sama dari pengamatan makroskopis dan mikroskopis setiap isolat.

Warna koloni berdasarkan pengamatan makroskopis cenderung ada yang berwarna putih, kream dan ada yang keunguan, hal ini sesuai dengan Sutejo et al., (2008)yang menyatakan sebagian besar isolat Fusarium spp. yang diperolehnya memiliki koloni yang berwarna putih atau disertai warna ungu atau merah muda pada pusat koloninya. Menurut Sari et al., (2017), Leslie dan Sumerell, (2006) warna koloni untuk setiap kelompok Fusarium spp. didominasi oleh warna putih, tetapi beberapa isolat F. oxysporum f. sp. cubense juga memiliki warna koloni merah muda, ungu muda, dan krem.

Pengamatan secara mikroskopis menunjukkan bahwa isolat cendawan yang diperoleh memiliki makrokonidia dan juga mikrokonidia.

Makrokonidia yang banyak dijumpai dalam jumlah yang melimpah dari semua isolat realtif sama yaitu berbentuk bulan sabit yang memanjang, atau berbentuk pipih memanjang dengan kedua ujungnya runcing dan memiliki 23 sekat. Hal ini sesuai dengan Sutejo et al.(2008), Leslie dan Sumerell (2006) menerangkan bahwa makrokonidium sangat melimpah, berbentuk sabit yang ramping, dinding tebal dan halus, dengan apikal sel yang runcing dan footshaped (menukik) pada bagian sel bawahnya.

Mikrokonidia yang dijumpai pada semua isolat juga relatif sama ada yang berbentuk lonjong, panjang, bagian tengah ramping dan kedua ujung tumpul, dan ada juga mikrokonidia yang berbentuk oval. Menurut Sutejo et al., (2008) F. oxysporum memiliki mikrokonidium yang sangat banyak, pada umumnya bersel tunggal, berbentuk oval sampai ginjal dan terbentuk pada false head.

\section{Kesimpulan}

Berdasarkan bentuk makroskopis dan mikroskopis dapat dismpulkan bahwa isolat yang diperoleh adalah jenis Fusarium oxysporum penyebab penyakit moler pada tanaman bawang merah di Kabupaten Enrekang

Diharapkan untuk penelitian lanjutan dilakukan analisa secara fisiologi bahkan molekuler dengan membandingkan isolat asal Kabupaten Enrekang dengan isolat asal provinsi lain untuk keragaman genetik dan penetuan spesies

Penelitian ini adalah satu bagian dari penelitian hibah Kemenristek Dikti dengan judul induk eksplorasi cendawan patogen pada tanaman bawang merah (Allium ascolonicum L) di Kabupaten Enrekang.

\section{Daftar Pustaka}

\section{Artikel Jurnal:}

Deden dan Umiyati, U. (2017). Pengaruh inokulasi Trichoderma $\mathrm{sp}$ dan varietas bawang merah terhadap 
penyakit moler dan hasil tanaman bawang merah (Allium ascalonicum L ) The effect of Trichoderma sp inoculation and shallot " Bawang merah " variety on moler diseases and yield of shallo. Kultivasi, 16(2), 340-348.

https://doi.org/https://doi.org/10.24198/kultivasi.v16i2 .12213

Fourie, G., Steenkamp, E. T., Gordon, T. R., \& Viljoen, A. (2009). Evolutionary Relationships among the Fusarium oxysporum f . sp . cubense Vegetative Compatibility Groups $\square$. Applied and Environmental Microbiology, 75(14), 4770-4781. https://doi.org/10.1128/AEM.00370-09

Isniah, U. S. dan W. (2015). Eksplorasi Fusarium Nonpatogen untuk Pengendalian Penyakit Busuk Pangkal pada Bawang Merah Exploration of Nonpathogenic Fusarium for the Control of Basal Rot Disease on Shallot. Fitopatologi, 11(Bps 2014), 1422. https://doi.org/10.14692/jfi.13.1.14

Ita Aprilia, Awang Maharijaya, S. dan S. W. (2020). Keragaman Genetik dan Ketahanan terhadap Penyakit Layu Fusarium ( Fusarium oxysporum f . sp cepae ) Bawang Merah ( Allium cepa L . var . aggregatum ) Indonesia. Hortikulura Indonesia, 11(April), 32-40. https://doi.org/http://dx.doi.org/10.29244/jhi.11.1.3240

Karim, H. A., HG, M. Y., Kandatong, H., Hikmahwati \& Fitrianti. (2020). Uji Produktivitas Berbagai Varietas Jagung (Zea mays L.) Hibrida dan Non Hibrida yang Sesuai pada Agroekosistem Kabupaten Polewali Mandar. Agrovital ..., 5(2015), 25-29. http://journal.lppmunasman.ac.id/index.php/agrovital/article/view/635

Nugroho, A. W. (2015). Potensi Jamur Perakaran sebagai Agens Pengendalian Hayati Penyakit Moler ( Fusarium oxysporum f . sp . Cepae ) pada Bawang Merah Potential of Root-Colonizing Fungi as Biocontrol Agent of Moler Desease ( Fusarium oxysporum f . sp . Cepae ) on Shallot. Agrosains, 17(1), 4-8. https://doi.org/https://doi.org/10.20961/agsjpa.v17i1.1 8656

Prakoso Ega Bramantya, S. W. dan H. N. (2016). Uji Ketahanan Berbagai Kultivar Bawang Merah ( Allium Ascalonicum ) terhadap Infeksi Penyakit Moler ( Fusarium oxysporum f . sp . cepae ) Endurance Test on Different Cultivars Shallots (Allium ascalonicum ) Against Infectious. Plumula, 5(1).

Quyen, T. V., Hoang, C., Tin, T., \& Khoa, N. D. (2017). Disease-reducing effects of antagonistic soil bacteria on Fusarium basal rot of shallot caused by Fusarium oxysporum in Vĩnh Châu, Sóc Trăng. Can Tho University Journal of Science, 6, 31-37. https://doi.org/10.22144/ctu.jen.2017.024

Sari, W., Wiyono, S., Nurmansyah, A., Munif, A., Poerwanto, R., \& Bogor, I. P. (2017). Keanekaragaman dan Patogenisitas Fusarium spp . Asal Beberapa Kultivar Pisang Diversity and Pathogenicity of Fusarium spp . Isolated from Several Banana Cultivars. Fitopatologi, 13(November). https://doi.org/10.14692/jfi.13.6.216
Sianipar, J. F. ; M. N. R. (2018). Karakterisasi dan Evaluasi Morfologi Bawang Merah Lokal Samosir (Allium ascalonicum L.) pada Beberapa Aksesi di Kecamatan Bakti Raja. Journal of Chemical Information and Modeling, 53(9), 1689-1699.

Suprapto Edy Santoso, Loekas Soesanto, dan T. A. D. H. (2007). PENEKANAN HAYATI PENYAKIT MOLER PADA BAWANG MERAH DAN PSEUDOMONAS FLUORESCENS P60. HPT Tropika, 7(1), 53-61. https://doi.org/https://doi.org/10.23960/j.hptt.17\%25p

Susanti, D. M., \& Wiyatiningsih, S. (2016). Characterization of isolates of Fusarium oxysporum $f$ Cepae Moler Cause Shallot of Diseases In The Region of Nganjuk and Probolinggo. Plumula, 5(2), 153-160. http://www.ejournal.upnjatim.ac.id/index.php/plumula /article/view/765

Sutejo, A. M., Priyatmojo, A., \& Wibowo, A. (2008). Morphological identification of several fusarium species. Perlindungan Tanaman Indonesia, 14(1), 7 13.

Buku :

Leslie, F. J. and B. A. S. (2006). The Fusarium Laboratory Manual (first). Blackwell publishing.

Tjitrosoepomo Gembong. (2010). Taksonomi Tumbuhan (Spermatophyta).

Skripsi :

Zulfikar. (2017). Tingkat Penggunaan Pestisida pada Tanaman Bawang Merah di Kecamatan Anggeraja, Kabupaten Enrekang [Departemen Hama dan penyakit Tumbuhan, Fakultas Pertanian, Universitas Hasanuddin].

http://digilib.unhas.ac.id/uploaded_files/temporary/Di gitalCollection/MDJmMDE1ZTYxYmY1ZTdiYzYw YmZlNzZiMTg5M2MxYmZlYWIwNTgwYw==.pdf

Internet Information

Badan Pusat Statistik. (2019). Kabupaten Enrekang Dalam Angka 2018. https://enrekangkab.bps.go.id

Badan Pusat Statistik. (2018). Kabupaten Enrekang Dalam Angka 2017. https://enrekangkab.bps.go.id

Repostory:

Ratih Suskandi, sri yusnaini, K. H. dan L. W. (2017). Identifikasi hama dan penyakit pada tanaman bawang putih sebagai upaya pendukung ketahanan pangan nasional. Jurusan Agroteknologi, Fakultas Pertanian, Universitas Lampung 